Short Communication

\title{
Genetic alterations in the coding region of the bak gene in uterine cervical carcinoma
}

\author{
KMY Wani' ${ }^{1,2,3}$, NG Huilgol'2, T Hongyo', H Ryo', K Shah ${ }^{2}$, N Chatterjee', CKK Nair ${ }^{3}$ and T Nomura*,I \\ 'Department of Radiation Biology and Medical Genetics, Graduate School of Medicine, Osaka University, Osaka 565-087I, Japan; '2Division of Radiation \\ Oncology, Nanavati Hospital and Medical Research Centre, Mumbai 400056, India; ${ }^{3}$ Biochemistry of Stress Response Section, Radiation Biology Division, \\ BARC, Mumbai 400085, India
}

Carcinoma of the uterine cervix remains the fifth most common female neoplasm worldwide. It appears that an early event is infection by human papilloma viruses (HPV) (Lorincz et al, 1987). However, not all patients with HPV infection develop invasive cancer, implying that additional molecular alterations may contribute to the multistep carcinogenesis process. These alterations most probably include activation of oncogenes or inactivation of tumour suppressor genes.

The bak gene, a recently identified member of the Bcl-2 family of apoptosis regulatory genes, has been shown to function as a potent inducer of apoptosis (Chittenden et al, 1995b; Kiefer et al, 1995). It has been mapped to the chromosome $6 \mathrm{p} 21.3$ (Herberg et al, 1998). A high incidence of loss of heterozygosity was found at this region in human cervical cancer (Kersemaekers et al, 1998), suggesting the involvement of a tumour suppressor gene. Since transformation of the cervical epithelial tissue to carcinoma is associated with the progressive inhibition of apoptosis (Nair et al, 1999) and bak-mediated apoptosis occurs in these cells (Krajewski et al, 1996), abrogation of this bak-mediated apoptosis could lead to transformation of the cervical epithelium. The bak gene may be acting as a tumour suppressor gene in cervical carcinoma.

We, therefore, studied the potential role of the bak gene as a tumour suppressor gene in cervical carcinoma by analysing the coding region for the presence of mutations and assessed its relation to the response to radiotherapy.

* Correspondence: Dr T Nomura; Department of Radiation Biology and Medical Genetics, Graduate School of Medicine, Osaka University, B4, 2 2 Yamada-Oka, Suita, Osaka 565-087I, Japan;

E-mail: tnomura@radbio.med.osaka-u.ac.jp

Received 3 July 2002; revised 2 January 2003; accepted 5 March 2003

\section{PATIENTS AND METHODS}

\section{Cervix cancer cases and radiotherapy}

Biopsied specimens from 42 patients with cervical carcinoma were obtained with informed consent prior to the initiation of radiotherapy at the Nanavati Hospital. The average age of the patients at biopsy was $51.6 \pm 3.9$ years (mean $\pm 95 \% \mathrm{CI}$ ). Patients were classified as 12 stage II cases and 30 stage III cases according to the criteria defined by the Federation of Gynecologists and Oncologists. All patients were irradiated with ${ }^{60} \mathrm{Co} \gamma$-rays by Theratron 780C (Atomic Energy of Canada Ltd, Chalk River, ON, Canada), a telecobalt equipment. Patients were treated at a dose rate of $1.2-1.4 \mathrm{~Gy} \mathrm{~min}^{-1}$ with a parallel opposed field, box technique or with multiple beams to encompass the entire pelvic disease. The upper margin of the field was placed at the L5/S1 junction, whereas the lower margin included the lowest palpable disease with a centimetre of margin. All patients received $50 \mathrm{~Gy}$ in 5 weeks with conventional fractionation ( $2 \mathrm{~Gy}$ daily for 5 weeks with no radiation on Saturday and Sunday). A boost with brachytherapy or with reduced field of external radiation was delivered after a gap of 8-10 days of external radiation. A minimum of $70 \mathrm{~Gy}$ was delivered with a maximum dose of $74 \mathrm{~Gy}$ (Huilgol et al, 1988). Patients were assessed for response within a week of conclusion of irradiation. The initial response as assessed clinically was categorised as complete or partial by the WHO criterion (WHO, 1979). Briefly, complete response is defined as complete regression of clinically detectable tumour, while partial is anything less than complete response but more than $50 \%$ of the initial tumour burden (Huilgol and Chatterjee, 1996).

Serial paraffin sections ( $5 \mu \mathrm{m}$ thickness) were made and stained with haematoxylin and eosin. Following the microscopic view, parts of unstained paraffin sections containing tumour tissues were scraped using a sterile surgical blade under the microscope and used for DNA extraction. As controls, paraffin sections of nonneoplastic cervical tissue specimens taken from 32 patients undergoing hysterectomy at Nanavati Hospital for various 
non-neoplastic uterine diseases (30 chronic endocervicitis tissues and two normal cervix tissues from endometroid adenocarcinoma patients) were examined. The average age of the patients was $44.9 \pm 3.8$ years (mean $\pm 95 \% \mathrm{CI})$.

\section{Examination of bak mutation}

PCR amplification followed by SSCP analysis and direct sequencing was carried out to detect mutations. Briefly, DNA was extracted from microdissected paraffin-embedded sections using the DNeasy tissue kit (QIAGEN Inc., Valencia, CA, USA), and exons 3, 4 and 6 of the bak gene were amplified by PCR (Geneamp PCR system 9700; Perkin-Elmer, Norwalk, CA, USA). The primer

A
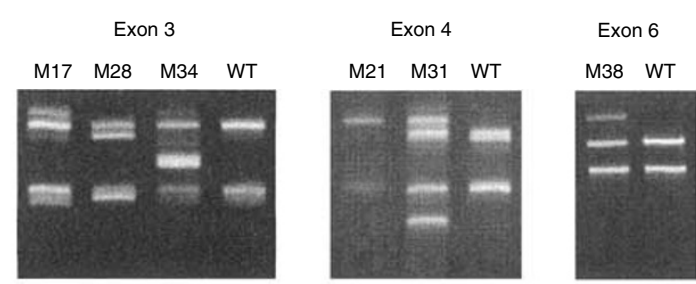

B

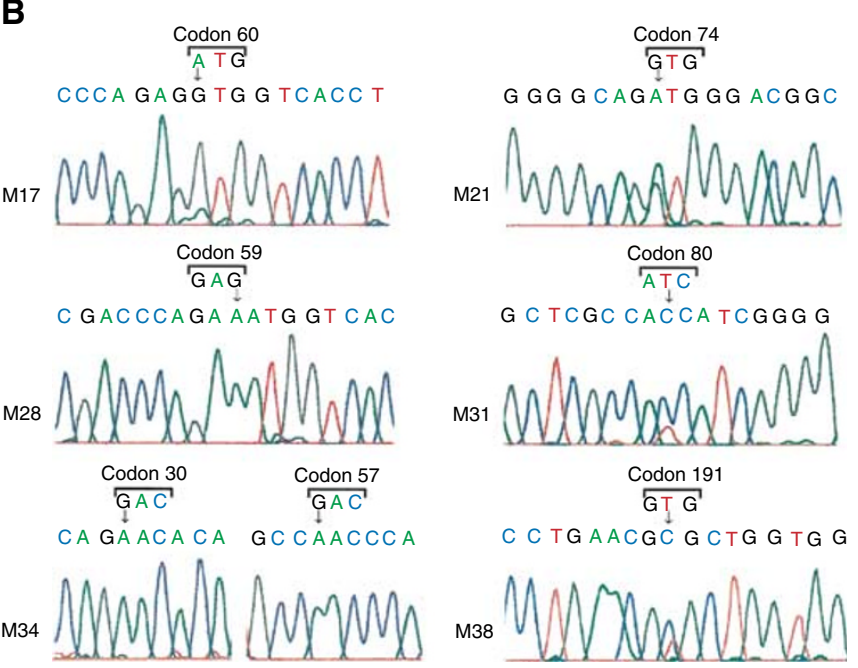

Figure I Detection of bak mutations in cervical carcinoma by cold-SSCP and direct sequencing. (A) Cold-SSCP profiles. PCR products from tumour DNA were run alongside a wild-type (WT) control (human lymphocyte DNA). Bands showing altered mobility were observed in six cervical cancer cases (MI7, 28, 34 for exon 3, M2I, 3I for exon 4 and M38 for exon 6). (B) Sequencing profiles of the bands showing altered mobility on the SSCP gel. Arrows indicate the bases altered from wild type to mutant type. pairs used for PCR amplification were $5^{\prime}$-TGCCTCCCTGAAGATGTCCT- $3^{\prime}$ and $5^{\prime}$-TGACTCCCAGCTTTGATCCT- $3^{\prime}$ for exon 3 , 5'-GGCAGGGTATGGTATGGTTG- $3^{\prime}$ and $5^{\prime}$-TCCCGACTGCCTGGTTACTG-3' for exon 4 , and $5^{\prime}$-GCAAGGGAACAGAGAAGGCA- $3^{\prime}$ and $5^{\prime}$-TGACCACCTTGTTTCTCCCG-3' for exon 6 as reported previously (Kondo et al, 2000). PCR products were subjected to SSCP without radioisotopes (cold-SSCP) (Hongyo et al, 1993). The optimal temperatures for electrophoresis were $25^{\circ} \mathrm{C}$ for exons 3 and 6 and $20^{\circ} \mathrm{C}$ for exon 4 . The SSCP bands, which showed altered mobility as compared to the wild-type control (human lymphocyte DNA), were extracted from the gel and reamplified by PCR to enrich the mutated alleles (Figure 1A). The mutated alleles were purified using the QIAquick PCR purification kit (QIAGEN Inc.). Direct sequencing was performed by the dideoxy chain termination method using the Big Dye Terminator cycle sequencing kit (Perkin-Elmer) and the automated DNA sequencer (ABI prism 3100 genetic analyser; PerkinElmer) (Figure 1B). The same primers were used for both PCR and direct sequencing. DNA extraction, PCR-SSCP analysis and sequencing of the mutated alleles were repeated more than twice to rule out the possibility of contamination and artifacts.

Statistical analysis was carried out by the SPSS statistical system (SPSS Inc., Chicago, IL, USA).

\section{RESULTS AND DISCUSSION}

Six transition type mutations and one silent mutation of the bak gene were observed in 42 cervical cancer specimens (Table 1). Four mutations were found in exon 3 of the bak gene in three cases: two in exon 4 in two cases and one in exon 6 in one case. One case showed a double mutation in exon 3 . No sequence alterations were found in any of the 32 non-neoplastic cervical tissues. We have, for the first time, shown a significant increase of mutations in the functional domain of the bak gene in human cervical carcinoma. In this study, mutations in the bak gene occurred more frequently in advanced-stage tumours $(16.7 \%$ in stage III $v s 8.3 \%$ in stage II), although the difference was not statistically significant. It may be a late event in cervical carcinogenesis. This is in agreement with studies of the bak gene in gastric and colorectal cancers where most of the mutations occurred at advanced stage (Kondo et al, 2000). Furthermore, cervical cancer tissues with bak mutations showed a decreased response to radiotherapy in comparison to those without bak mutation (Table 2). However, the difference was not statistically significant because of the small sample size $(P=0.12)$

$\mathrm{Bak}$, which is a member of the Bcl-2 family, shows the presence of the $\mathrm{BH} 1, \mathrm{BH} 2$ and $\mathrm{BH} 3$ homology domains and a membraneanchoring region (Chittenden et al, 1995a). The bak gene functions by binding and inhibiting the antiapoptotic molecule $\mathrm{Bcl}-\mathrm{x}_{\mathrm{L}}$, thereby inducing apoptosis. The $\mathrm{BH} 3$ domain of the bak gene, encoded by exon 4 , has been shown to be responsible for its ability to induce apoptosis as well as bind Bcl- $\mathrm{x}_{\mathrm{L}}$ (Chittenden et al, 1995a), while constructs lacking exon 3 did not influence the cytotoxicity

Table I Mutations in coding region of the bak gene in cervical carcinoma

\begin{tabular}{|c|c|c|c|c|c|c|}
\hline & \multirow[b]{2}{*}{ Stage } & \multirow[b]{2}{*}{ No. of cases } & \multirow[b]{2}{*}{ Cases with mutation } & \multicolumn{3}{|c|}{ Mutations at } \\
\hline & & & & exon 3 & exon 4 & exon 6 \\
\hline \multirow[t]{2}{*}{ Cancerous tissues } & $\|$ & 12 & I & $1^{\mathrm{a}}$ & 0 & 0 \\
\hline & III & 30 & 5 & $3^{b}$ & $2^{c}$ & $1^{d}$ \\
\hline Total & - & 42 & $6^{e}$ & 4 & 2 & 1 \\
\hline Non-neoplastic tissues & - & 32 & 0 & 0 & 0 & 0 \\
\hline
\end{tabular}


Table 2 Pre-existing bak mutations in stage III cervical carcinomas and their response to radiotherapy

\begin{tabular}{lccc}
\hline & & \multicolumn{2}{c}{ Response to radiotherapy } \\
\cline { 3 - 4 } bak mutation $^{\mathbf{a}}$ & No. of cases & Partial & Complete $^{\mathbf{b}}$ \\
\cline { 3 - 4 }+ & 4 & $3^{c}$ & 1 \\
- & 26 & 8 & 18 \\
\hline
\end{tabular}

aissense mutations detected in the biopsied specimens taken prior to radiotherapy.

${ }^{b} \mathrm{WHO}$ criterion $(9,10) .{ }^{c} P=0.12$ by Fisher's exact test.

of bak in Rat- 1 cells. Deletion of the membrane-anchoring region of the bak gene, located in exon 6, was found to reduce its cytotoxicity because of altered subcellular localisation. We have identified missense mutations in the $\mathrm{BH} 3$ domain in two specimens and mutation in the membrane-anchoring region in one specimen. Since these mutations occurred in domains responsible for Bcl- $\mathrm{x}_{\mathrm{L}}$ binding and subcellular localisation, it is likely that these mutations resulted in loss of proapoptotic function of the bak gene in these specimens and caused the reduced response to radio-

\section{REFERENCES}

Chittenden T, Flemington C, Houghton AB, Ebb RG, Gallo GJ, Elangovan B, Chinnadurai G, Lutz RJ (1995a) A conserved domain in Bak, distinct fron $\mathrm{BH} 1$ and $\mathrm{BH} 2$, mediates cell death and protein binding functions. EMBO J 14: $5589-5596$

Chittenden T, Harrington EA, O' Connor R, Flemington C, Lutz RJ, Evan GI, Guild BC (1995b) Induction of apoptosis by the Bcl-2 homologue Bak. Nature (London) 374: 733-736

Herberg JA, Phillips S, Beck S, Jones T, Sheer D, Wu JJ, Prochazka V, Barr PJ, Kiefer MC, Trowsdale J (1998) Genomic structure and domain organization of the human Bak gene. Gene 211: 87-94

Hongyo T, Buzzard GS, Calvert RJ, Weghorst CM (1993) 'Cold SSCP': a simple rapid and non-radioactive method for optimized singlestrand conformation polymorphism analysis. Nucleic Acid Res 21: $3637-3642$

Huilgol NG, Chatterjee NA (1996) Assessment of chlorpromazine as radiation sensitizer and protector. Indian J Cancer 31: 195-200

Huilgol NG, Mehta AR, Kulkarni VB (1988) Hypofractionated external radiation with high and low dose rates in the treatment of advanced cancer of cervix. Int J Radiat Biol Phys 14: 577-579

Kersemaekers AF, Kenter GG, Hermans J, Fleuren GJ, Van De Vijver MJ (1998) Alellic loss and prognosis in carcinoma of the uterine cervix. Int J Cancer (Pred Oncol) 79: $411-417$ therapy. In two cervical cancer tissues, however, missence mutations were found in exon 3. Further study is required to know the contribution of mutations in exon 3 to cervical carcinogenesis.

The bak gene has been shown to induce apoptosis in a $p 53$ independent manner in lung cancer cell lines (Pataer et al, 2000). In most cervical carcinomas, $p 53$ is nonfunctional either because of HPV infection or because of mutations in the $p 53$ gene (Lazo, 1999). In the absence of functional $p 53$, bak-mediated apoptosis may occur in the cervical epithelium. Abrogation of this bakmediated apoptosis could lead to the development of cervical carcinomas at least in a subset of cases and results in the reduced response to radiotherapy.

\section{ACKNOWLEDGEMENTS}

This work was supported by the Research for the Future (JSPS) and the Japanese Ministry of Education, Culture, Science and Technology. We also thank Dr H Nakajima, Miss M Maeda and $\mathrm{Mr}$ $S$ Adachi for preparing the manuscript.
Kiefer MC, Brauer MJ, Powers VC, Wu JJ, Umansky SR, Tomei LD, Barr PJ (1995) Modulation of apoptosis by the widely distributed Bcl-2 homologue Bak. Nature (London) 374: 736-739

Kondo S, Shinomura Y, Miyazaki Y, Kiyohara T, Tsutsui S, Kitamura S, Nagasawa Y, Nakahara M, Kanayama S, Matsuzawa Y (2000) Mutations of the bak gene in human gastric and colorectal cancers. Cancer Res 60: 4328-4330

Krajewski S, Krajewska M, Reed JC (1996) Immunohistochemical analysis of in vivo patterns of Bak expression, a proapoptotic member of the Bcl-2 protein family. Cancer Res 56: $2849-2855$

Lazo PA (1999) The molecular genetics of cervical carcinoma. Br J Cancer 80: $2008-2018$

Lorincz AT, Temple GF, Kurman RJ, Jenson AB, Lancaster WD (1987) Oncogenic association of specific human papillomavirus types with cervical neoplasia. J Natl Cancer Inst 79: 671-677

Nair P, Nair KM, Jayaprakash PG, Pillai MR (1999) Decreased programmed cell death in the uterine cervix is associated with high risk human papillomavirus infection. Pathol Oncol Res 5: 95-103

Pataer A, Fang B, Yu R, Kagawa S, Hunt KK, McDonnell TJ, Roth JA, Swisher SG (2000) Adenoviral Bak overexpression mediates caspasedependant tumor killing. Cancer Res 60: 788-792

WHO (1979) WHO Handbook for Reporting Results of Cancer Treatment. WHO offset publication no. 48. Geneva: World Health Organization 